\title{
Secretory $\gamma \mathrm{A}$ in Normal Urine
}

\author{
John Bienenstock and Thomas B. Tomasi, JR. \\ From the Rheumatic Disease Unit, Department of Medicine, State University of \\ New York at Buffalo and The Buffalo General Hospital, Buffalo, New York
}

A BSTRACT The physicochemical nature of $\gamma \mathrm{A}$ was investigated in normal male and female urine concentrated approximately 1000 times. Sucrose density gradient ultracentrifugation and Sephadex G-200 chromatography revealed that urinary $\gamma \mathrm{A}$ has sedimentation properties intermediate between $19 \mathrm{~S}$ and $7 \mathrm{~S}$ molecules. Isolation of urinary $\gamma \mathrm{A}$ by DE 52 chromatography free of other immunoglobulins with subsequent antigenic analysis showed that the urinary $\gamma \mathrm{A}$-molecule is antigenically indistinguishable from the $\gamma \mathrm{A}$-molecules found in other external secretions and has a corrected sedimentation coefficient of $11.8 \mathrm{~S}$. In addition, like other secretory $\gamma \mathrm{A}$-molecules and unlike serum polymeric $\gamma \mathrm{A}$, urinary $\gamma \mathrm{A}$ resisted mild reductive measures with $0.1 \mathrm{M} \beta$-mercaptoethanol. Free or unattached secretory "piece" was found in all normal urines tested and in agammaglobulinemic urine. Secretory "piece" antigenic determinants were also found in ureteric urine. The average daily excretion of urinary $\gamma \mathrm{A}$ was $1.1 \mathrm{mg}$. The maximum excretion of urinary $7 \mathrm{~S}$ $\gamma \mathrm{G}$ per $24 \mathrm{hr}$ was approximately $3 \mathrm{mg}$.

\section{INTRODUCTION}

A major part of the urinary $\gamma$-globulin has been found to consist of subunits or fragments of immunoglobulins in the form of $\mathrm{L}$ chains and $\mathrm{Fc}$ and $F^{\prime} c$ fragments $(1-6)$. Glomerular filtration appears to be the primary route of excretion of circulating serum $\gamma$-globulin fragments such as $\mathrm{L}$

This work was presented in part at the American Society of Clinical Research, Atlantic City, N. J., May 1967.

Address requests for reprints to Dr. John Bienenstock, Department of Medicine, State University of New York at Buffalo, 100 High Street, Buffalo, N. Y. 14203.

Received for publication 27 October 1967 and in revised form 7 December 1967. chains and $\mathrm{Fc}$ fragments $(1,4)$. We have, however, recently found evidence that the $F^{\prime} c$ may be derived at least in large part from urinary $\mathrm{Fc}$ by proteolysis (6). In addition to these fragments and subunits native $7 \mathrm{~S} \gamma \mathrm{G}$ has been shown to exist in small amounts in normal urine by Franklin (3), and a high molecular weight form of $\gamma \mathrm{A}$ has been described by Tomasi and Zigelbaum (7) and Turner and Rowe (8). However, it is generally accepted that 19S $\gamma \mathrm{M}$ is not a normal constituent of urine, and $\mathrm{H}$ chain fragments of $\gamma \mathrm{M}$ have not been identified in normal urine.

This report is concerned with an investigation into the nature of $\gamma \mathrm{A}$ in normal urine. It was found that $\gamma \mathrm{A}$ constitutes a significant fraction of the total urinary imunoglobulins and that in addition, urinary $\gamma \mathrm{A}$ is primarily of high molecular weight and indistinguishable from the secretory form associated with certain other external secretions (9).

\section{METHODS}

Specimens. 24-hr urine samples were collected from healthy male and female volunteers and preserved in $0.1 \%$ sodium azide. None of the females were menstruating at the time of the collection. Samples were kept at $4^{\circ} \mathrm{C}$ overnight and then filtered on Whatman No. 1 paper. Urine was concentrated by negative pressure dialysis at 28 inches of mercury in Visking ${ }^{1} 8 / 32$ membranes. All samples were concentrated about 1000 times and centrifuged at $10,000 \mathrm{rpm}$ in the cold before storing at $-20^{\circ} \mathrm{C}$ until used. No 24-hr specimens of urine contained more than $80 \mathrm{mg}$ of protein by Folin (10) or biuret (11) reactions.

Antisera. Antisera were prepared in rabbits and goats by immunization with antigens in complete Freund's adjuvant. Anti-L chain antisera were obtained by immunization with papain Fab fragments of $\gamma \mathrm{G}$ isolated by starch block electrophoresis and subsequent gel filtra-

\footnotetext{
1 Union Carbide Corp., Visking Div., Chicago, Ill.
} 
tion on Sephadex ${ }^{2}$ G-100. This antiserum showed both $\kappa$ - and $\lambda$-chain reactivity. $\boldsymbol{\gamma}$-chain-specific antisera were obtained by immunization with the papain $F c$ fragment. Trace contamination of the Fc preparation with Fab occurred so that this antiserum was absorbed with Bence Jones proteins of $\alpha$ - and $\lambda$-types to produce a specific antiserum that reacted only with $\gamma \mathrm{G}-$, and $\mathrm{Fc}$ and $\mathrm{F}^{\prime} \mathrm{c}$ (12) fragments. $\gamma \mathrm{A}-$ and $\gamma \mathrm{M}$-antisera were commercial preparations ${ }^{8}$ or were prepared by immunization with purified immunoglobulin preparations and made specific by suitable absorption with $\gamma \mathrm{G}$ and $\mathrm{L}$ chains. An antiserum which reacted only with $\gamma \mathrm{A}$-secretory "piece" was made in the burro by immunization with human colostral $\gamma \mathrm{A}$ (kindly donated by Dr. J. Bellanti) or by immunization of rabbits with colostral or salivary $\gamma \mathrm{A}$. These antisera were absorbed with Cohn Fraction II and a euglobulin fraction of a macroglobulinemic human serum and reacted only with $\gamma \mathrm{A}$ and secretory "piece." The antiserum when absorbed with concentrated normal human serum reacted only with secretory "piece." Both of these absorbed antisera reacted in addition with a macromolecular component present in saliva and colostrum in trace amounts and found in urine in larger quantities. This additional component, which has not been fully characterized, has an alpha mobility on electrophoresis and is not found in normal human sera. ${ }^{4}$

\section{Techniques}

Ouchterlony and immunoelectrophoretic analyses were performed as previously described (13). Analytical ultracentrifugation was carried out with a Spinco model $\mathrm{E}$ ultracentrifuge at $52,640 \mathrm{rpm}$ and $20^{\circ} \mathrm{C}$ with double sector cells. Sedimentation coefficients were calculated at infinite dilution from plots of $s_{20}$, against concentration. Density gradient ultracentrifugation with $10-40 \%$ sucrose gradients were performed according to methods outlined before (7).

Gel filtration and chromatography. Concentrated urine samples were subjected to gel filtration on Sephadex G-200 in $0.85 \%$ saline. Chromatography on DE 52 (Whatman) ${ }^{5}$ with stepwise elution was performed as previously described (14). Protein concentrations were measured by absorption at $280 \mathrm{~m} \mu$ in a Zeiss spectrophotometer, and by the Lowry modification of the Folin-Ciocalteau method.

Immunoglobulin quantitation. Quantitative immunoglobulin determination was performed by the radial diffusion technique (7) with goat antisera specific for $\gamma \mathrm{A}$ and a rabbit anti- $\gamma$-chain for $\gamma \mathrm{G}$. Standard calibration curves were constructed with $7 \mathrm{~S}$ serum $\gamma \mathrm{A}$ and a sample of colostral 11S $\gamma \mathrm{A}$ obtained as previously described (9). The standard curve obtained by use of the $11 \mathrm{~S} \gamma \mathrm{A}$ was used for quantitation of urinary $\gamma \mathrm{A}$. A calibration curve for $\gamma \mathrm{G}$ was prepared with $7 \mathrm{~S} \gamma \mathrm{G}$ isolated from normal serum by starch block electrophoresis and diethylamino-

\footnotetext{
2 Pharmacia Fine Chemicals Inc., Piscataway, N. J.

3 Hyland Laboratories, Los Angeles, Calif.

4 Bienenstock, J., and T. B. Tomasi. Unpublished observations.

5 R. A. Reeve Angel, Clifton, N. J.
}

ethyl (DEAE) chromatography. All standards were tested for homogeneity by analytical ultracentrifugation (at a concentration of at least $10 \mathrm{mg} / \mathrm{ml}$ ), disc electrophoresis, and by immunoelectrophoresis and Ouchterlony analysis with several potent anti-whole and anti- $\gamma$-globulin antisera.

\section{RESULTS}

Several investigators have demonstrated the efficacy of the method used for concentration of urinary protein samples $(15,16)$. Some doubt has, however, been expressed as to the percentage recovery of higher molecular weight proteins by the method (17). Serum was accordingly diluted 1000 times with saline and concentrated in $8 / 32$ Visking membranes. Full recovery of $\gamma \mathrm{G}, \gamma \mathrm{A}$, and $\gamma \mathrm{M}$ was demonstrated after concentration, within the experimental error of this method (approximately $10 \%)$. The Visking membranes were demonstrated to retain egg white lysozyme ( $\mathrm{mol} \mathrm{wt} 14$ 18,000 ) within the bag. Urinary filtrate lyophilized and redissolved to a concentration of 1000 times the original showed no immunological reactivity with an antiserum against whole human serum. Quantitative data relating to the recovery of free secretory "piece" were not obtained. Fig. 1 shows a typical Ouchterlony pattern with an antisecretory $\gamma \mathrm{A}$-antiserum that reacts with both secretory "piece" and $\gamma \mathrm{A}$. The additional urinary macromolecular component referred to earlier is seen closest to the antigen well. Free or unattached secretory "piece" diffuses ahead of the whole $\gamma \mathrm{A}$-molecule and is closest to the antiserum well. A similar pattern is seen with both female and male urine. Because the free "piece" diffuses rapidly and removes "piece"-specific antibodies there is no spurring of the secretory $\gamma \mathrm{A}$ over the serum $\gamma \mathrm{A}$. It was necessary, therefore, in order to study the immunological relationships of urinary $\gamma \mathrm{A}$ to that of serum as well as other secretions, to further purify the urinary $\gamma \mathrm{A}$-molecule and to separate it from unattached secretory "piece." A 10 day collection of urine was concentrated. (The 24 hr-samples were individually pooled and processed.) A total volume of $15 \mathrm{ml}$ of concentrated urine was placed on a column of Sephadex G-200, $4 \times 130 \mathrm{~cm}$ and eluted with $0.14 \mathrm{~m}$ saline. The elution pattern is seen in Fig. 2. $\gamma \mathrm{A}$ ( $\alpha$-chain determinants) was eluted in the second half of the first protein peak (pool 1). The reaction of the eluate fractions with a specific anti-"piece" anti- 

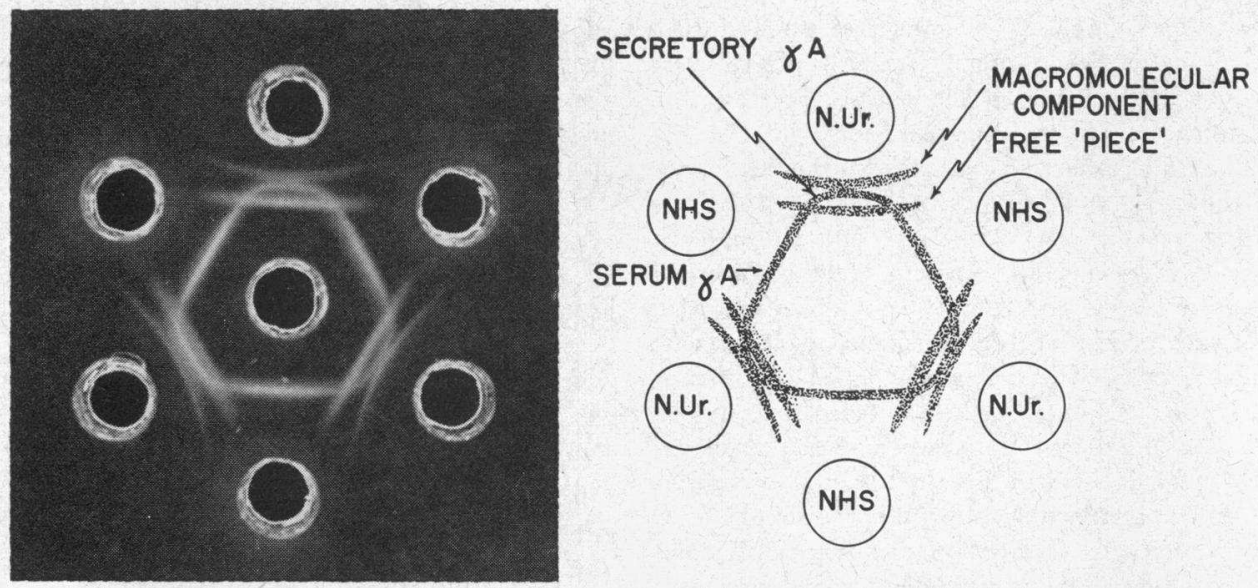

FIGURE 1 Ouchterlony plate showing antigenic character of urinary $\gamma \mathrm{A}$ and secretory "piece"; in urine. The central well contains an antiserum against colostral $11 \mathrm{~S}$ secretory $\gamma \mathrm{A}$ absorbed with Cohn Fraction II. The top well contained male urine, and the bottom urine wells were filled with female urine. N.Ur., normal urine; $N H S$, normal human serum.

serum was biphasic: first in the same tubes as the $\alpha$-chain reactivity (pool 1 ), second in a position corresponding to the end of the "7S peak" and the beginning of the albumin peak (pool 2). By antigenic analysis the first part of this biphasic reaction was subsequently shown to be due to secretory "piece" that is present as part of the 11S secretory $\gamma \mathrm{A}$-molecule and the second to unattached or free secretory "piece." The last and largest peak contains primarily urinary glycopeptides having a sedimentation coefficient of less than $1 \mathrm{~S}$. The additional macromolecular component with which the antisecretory antisera react (Fig. 2) is eluted in the ascending portion of the first peak.

When the $\gamma \mathrm{A}$-reactive material present in pool

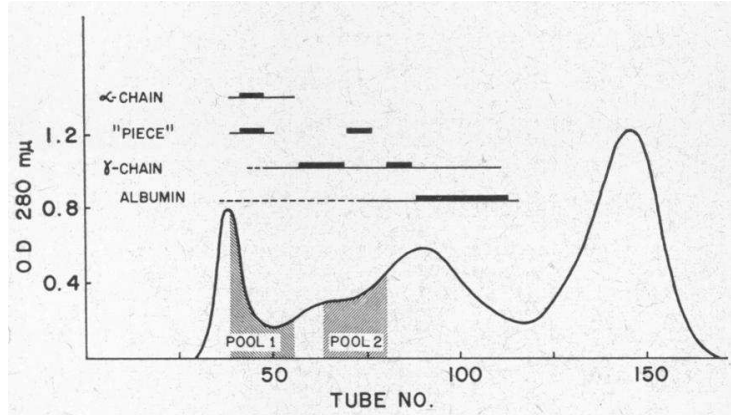

FIGURE 2 Gel filtration showing the elution pattern of a 10 day pool of urine on Sephadex G-200. The distributions in the chromatographic fractions of the various urinary components are shown by the horizontal black bars. Pool 1 contained all of the $\gamma$ A-reactive material. "Piece" determinants were present in both pool 1 and pool 2 .
1 was concentrated and rechromatographed on Sephadex G-200 it was again eluted in a position ahead of the $7 \mathrm{~S} \gamma \mathrm{G}$, but in a larger volume than the blue dextran marker used for measuring the void volume of the column (Fig. 3). $\gamma \mathrm{M}$ was not detected with an anti- $\mu$-chain antiserum in any of the samples. Analytical ultracentrifugation of pool 1 showed a trace component with a sedimentation coefficient of $19 \mathrm{~S}$, a second component at $10.7 \mathrm{~S}$, and a major component of $3.3 \mathrm{~S}$. This pattern was

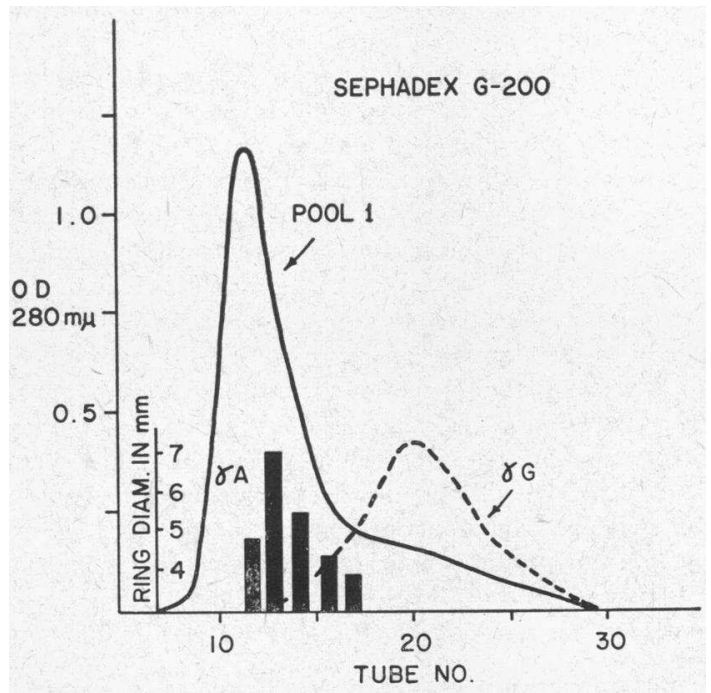

FIGURE 3 Rechromatography of pool 1 from Fig. 2 on Sephadex G-200. $\gamma \mathrm{A}$ (solid curve) has an elution position intermediate between the void volume and a $\gamma \mathrm{G}$ (dashed curve) marker. 


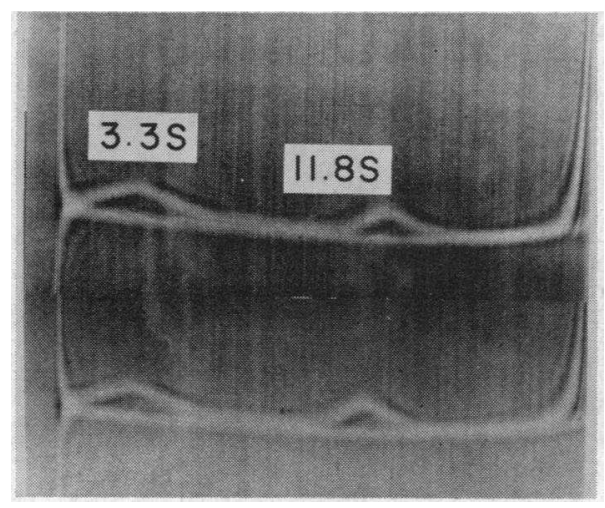

FIGURE 4 Analytical ultracentrifugation pattern of a purified urinary $\gamma \mathrm{A}$ fraction after DE 52 chromatography, at $52,640 \mathrm{rpm}, 56 \mathrm{~min}$ after full speed was attained. The upper frame is before and the lower frame is after incubation with $0.1 \mathrm{M} \beta$ mercaptoethanol. The $s^{\circ}{ }_{20, \infty}$ of urinary $\gamma \mathrm{A}$ was $11.8 \mathrm{~S}$. The second more slowly sedimenting 3.3S component is a urinary-specific component of unknown composition.

found consistently with six different urinary samples. The nature of the $3.3 \mathrm{~S}$ component is unclear from our experiments. From the elution position on a Sephadex G-200 column and the sedimentation characteristics the $3.3 \mathrm{~S}$ material is assumed to be constituted by highly asymmetric molecules. Its composition is uncertain and fractions containing this component (free of $\gamma \mathrm{A}$ ) do not react with

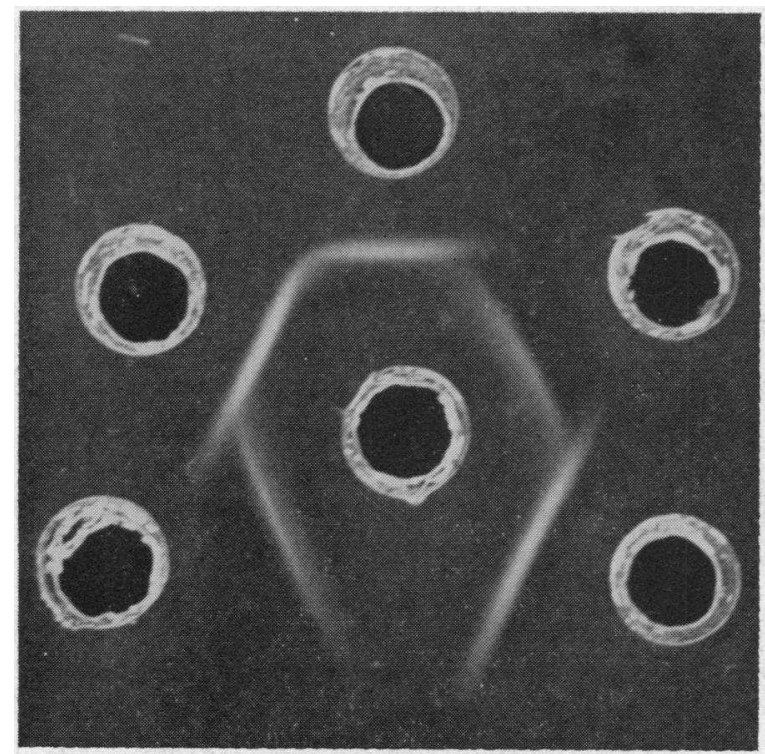

antisera against whole human serum or with any of the secretory antisera used in this study.

All of the $\gamma \mathrm{A}$-reactive material obtained from gel filtration (pool 1) was concentrated, dialyzed overnight against $0.01 \mathrm{~m}$ phosphate buffer, $\mathrm{pH}$ 7.4, and chromatographed on DE 52. Subsequent elution with $0.1 \mathrm{M}$ phosphate, $\mathrm{pH} 6.0$, produced a fraction rich in $\gamma \mathrm{A}$. Double diffusion in agar with an anti-whole human serum revealed a $\gamma \mathrm{A}$ precipitin arc and an additional component that was present in trace amounts and could not be detected on immunoelectrophoresis. Final recovery of $\gamma \mathrm{A}$ as compared to the original urine sample before gel filtration was approximately $20 \%$. After concentration, this specimen was subjected to analytical ultracentrifugation, the results of which are shown in Fig. 4. Two major components are recognized: one having a sedimentation coefficient $\left(s^{0}{ }_{20, w}\right)$ of $11.8 \mathrm{~S}$ and the other of $3.3 \mathrm{~S}$. The addition of $0.1 \mathrm{~m} \beta$-mercaptoethanol did not appreciably alter the sedimentation coefficient of $\gamma \mathrm{A}$ as shown in the lower half of Fig. 4.

Urinary $\gamma \mathrm{A}$ purified as described was then compared to normal human serum, 11S colostral $\gamma \mathrm{A}$, and whole concentrated saliva with antisecretory $\gamma \mathrm{A}$-antiserum as shown in Fig. 5. Urinary $\gamma \mathrm{A}$ is antigenically identical with salivary and colostral $\gamma \mathrm{A}$, serum $\gamma \mathrm{A}$ being deficient to all three. Reac-

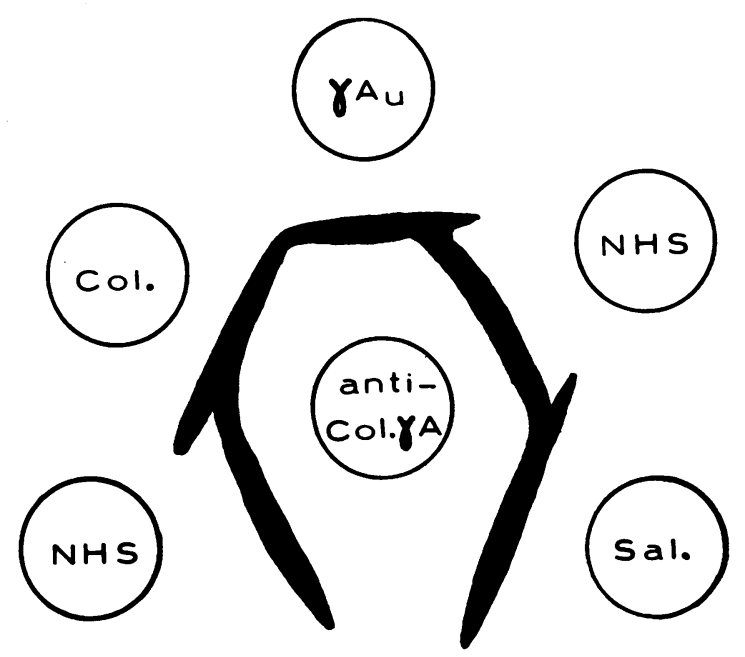

FIGURE 5 Ouchterlony plate showing antigenic relationship of $\gamma \mathrm{A}$ from normal human serum (NHS), colostrum $(C o l$.$) , urine (\gamma A u)$ and saliva $(S a l$.$) . The central well contains an antisecretory \gamma \mathrm{A}$-antiserum (anti-Col. $\gamma A)$ that reacts with both secretory "piece" and $\gamma \mathrm{A}-\mathrm{H}$ chain determinants. 
tions of identity were also shown among those secretory molecules sharing "piece" determinants using a specific antisecretory "piece" antiserum. Immunoelectrophoresis of the purified $\gamma \mathrm{A}$-fraction reveals precipitin arcs of the same mobility as serum $\gamma \mathrm{A}$ with both an antiserum 7S $\gamma \mathrm{A}$ and with secretory "piece" antisera (Fig. 6); this finding confirms the presence of secretory "piece" attached to the $\gamma \mathrm{A}$-molecule.

When pool 2 from the first Sephadex G-200 gel filtration (Fig. 2) containing free "piece" was concentrated, dialyzed against the starting buffer, and eluted on DE 52, most of the "piece" reactive material was eluted with $0.05 \mathrm{~m}$ phosphate buffer, $\mathrm{pH}$ 6.0. However, a small amount of "piece" reactive material was eluted with the lowest ionic strength buffer used (0.01 moles/liter, $\mathrm{pH} 7.4)$ together with $7 \mathrm{~S} \gamma \mathrm{G}$. Immunoelectrophoresis of this peak developed with anti- $\gamma$-chain and "piece" specific antisera reveals a single arc in the $\beta$ region with the characteristic mobility of free or unattached secretory "piece." Free "piece" eluted with $0.05 \mathrm{~m}$ buffer, $\mathrm{pH} 6.0$, is seen in the lower half of Fig. 7. This finding indicates that secretory "piece" is not attached to $\gamma \mathrm{G}$ in the urine. The mobility and character of the free "piece" arc are entirely similar to that found in agammaglobulinemic urine and saliva and that obtained with a "piece" preparation isolated by reduction and alkylation from colostral $\gamma \mathrm{A}$ (18).

Sucrose density gradient ultracentrifugation of six whole concentrated normal urines was performed together with normal human serum. The results are graphically shown in Fig. 8 with one typical sample. Quantitation of $\gamma \mathrm{A}$ was carried

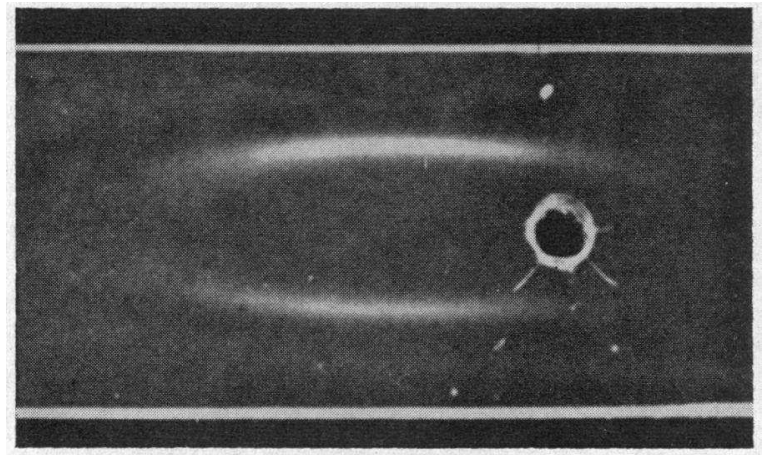

FIGURE 6 Immunoelectrophoretic pattern of a urinary $\gamma \mathrm{A}$ preparation showing precipitin arcs of comparable mobility with both anti- $\alpha$-chain (upper trough) and antisecretory (lower trough) antisera. The antisecretory antisera have been absorbed with normal serum and are "piece" specific. The anode is to the right.

out by the radial diffusion technique. Urinary $\gamma \mathrm{A}$ was shown to have a sedimentation position intermediate between that occupied by the $7 \mathrm{~S}$ and $19 \mathrm{~S}$ immunoglobulins of serum in keeping with the evidence for an $11 \mathrm{~S}$ secretory type of urinary $\gamma \mathrm{A}$.

In order to investigate whether the urinary $\gamma \mathrm{A}$ was derived from the renal tract higher than the bladder five samples of ureteric urine were obtained during ureteric catheterization and tested by double diffusion in agar after concentration. Secretory "piece" determinants were demonstrated in all these samples. However, all samples contained large amounts of serum proteins including serum type $\gamma \mathrm{A}$ and $\gamma \mathrm{G}$. The patients from whom samples were obtained had moderate or gross renal disease. Contamination of ureteric samples with serum proteins from trauma or indirect admixture with serum proteins through glomerular leakage

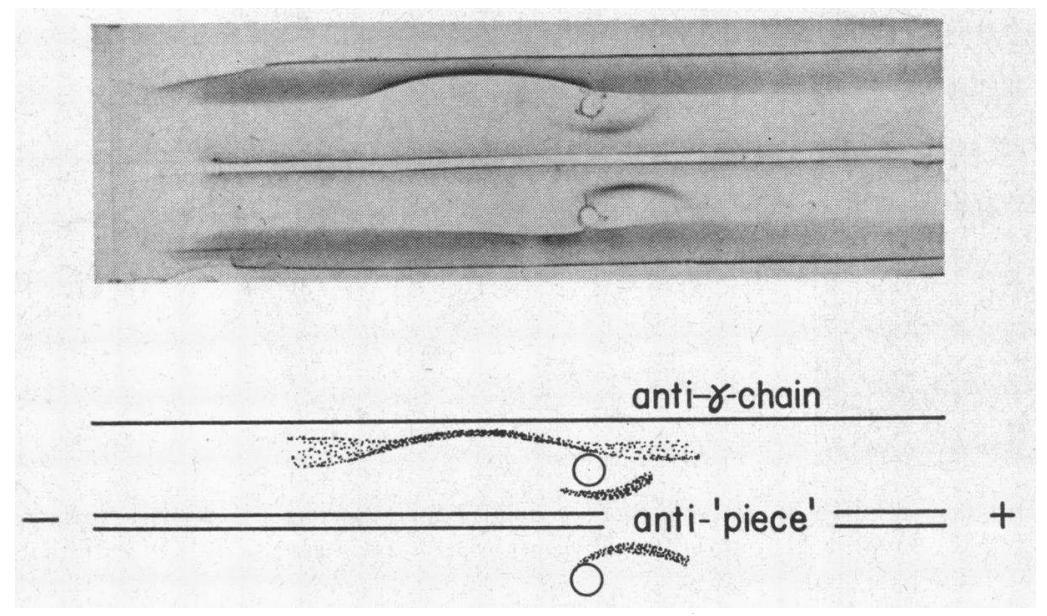

FIGURE 7 Stained immunoelectrophoretic pattern of fractions obtained with two separate buffers' on DE 52 . Starting sample was the urinary "piece"-reactive material, not bound to $\gamma \mathrm{A}$ (pool 2, Fig. 2). Upper well contains material eluted with $0.01 \mathrm{M}$ phosphate buffer, $\mathrm{pH}$ 7.4; lower well contains eluate obtained with $0.05 \mathrm{~m}$ phosphate buffer, $\mathrm{pH}$ 6.0. $\gamma \mathrm{G}$ and free "piece" arcs of differing mobilities are seen, indicating that "piece" is not attached to urinary $\gamma \mathrm{G}$. 


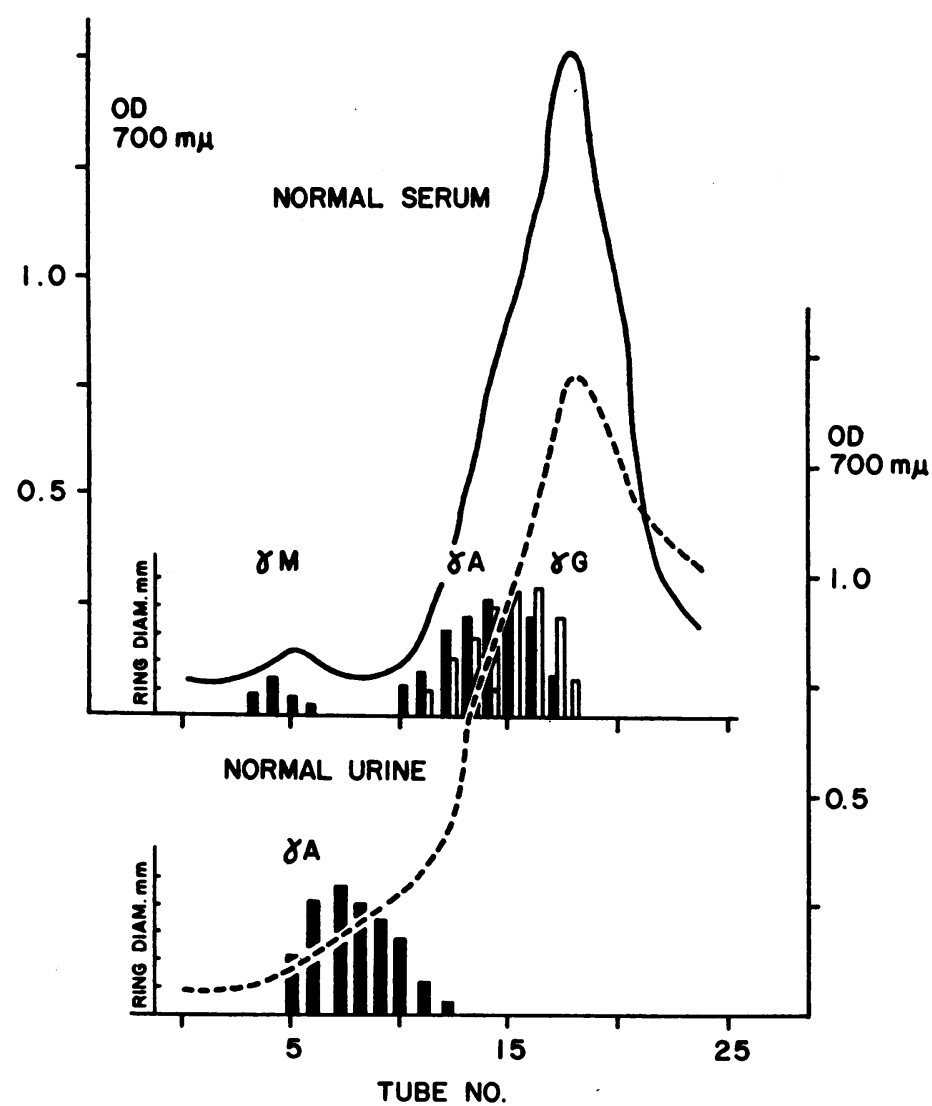

FIgURE 8 Sucrose density gradient (10$40 \%$ ) ultracentrifugation of serum and urine. Urinary $\gamma \mathrm{A}$ (dashed curve) is seen to have an intermediate position between $\gamma \mathrm{M}$ (19S) and serum $\gamma \mathrm{A}$ and $\gamma \mathrm{G}(7 \mathrm{~S})$. Urinary $\gamma \mathrm{G}$ is not shown since reactivity is seen from the $7 \mathrm{~S}$ region to the top of the gradient because of the presence of heavy chain-related fragments. were impossible to avoid, and insufficient material was available for fractionation studies. Therefore, no conclusions can be drawn as to whether the "piece" determinants in ureteric urine were attached to the intact $11 \mathrm{~S}$ secretory molecule, represented free "piece," or both.

Quantitation of $\gamma \mathrm{A}$ was performed by the radial diffusion technique on urines from 19 healthy volunteers: 6 females and 13 males. When serum $7 \mathrm{~S} \gamma \mathrm{A}$ was used as standard, the results were one-third to one-fourth lower than when colostral $\gamma \mathrm{A}$ was used for calibration of the standard curve. Since, as shown above, the majority of the urinary $\gamma \mathrm{A}$ is of the high molecular weight (11S secretory type) the colostral $\gamma \mathrm{A}$ calibration curve was used. The results are shown in Table I. Since no subunits or fragments of $\gamma \mathrm{A}$ were found in the low molecular weight fractions of the gel fltration experiments, the values obtained for excretion of $\gamma \mathrm{A}$ are probably reasonably accurate. The average daily excretion of $\gamma \mathrm{A}$ is, therefore, approximately $1.0 \mathrm{mg}$.
An attempt was made to quantitate urinary $\gamma \mathrm{G}$. However, it is known that in urine fragments of the $\gamma \mathrm{G}$-heavy chain are found, such as the Fc and $F^{\prime} c$ fragments $(2,5,6)$. When radial diffusion quantitative procedures were applied to urine with a specific anti- $\gamma$-chain antiserum two standards were compared: $7 \mathrm{~S} \gamma \mathrm{G}$-globulin and the papain Fc fragment. Since the smaller molecules diffuse faster, larger precipitin rings were found for the same concentration when compared to the native 7S immunoglobulin. Thus, the values obtained by reading ring diameters on the $7 \mathrm{~S}$ standard revealed higher concentrations than were obtained with the Fc fragment calibration curve and, therefore, they are overestimates of the amount of $\gamma$ G-globulin. Since it is not known whether the fragments represent precursor subunits or breakdown products of the parent molecules, the values for the $\gamma \mathrm{G}$ excretion per day which were obtained in this manner must represent a maximum figure. The results are shown in Table I. The average is $3.0 \mathrm{mg} /$ day. Daily indi- 
TABLE I

Immunoglobulin Quantitation in Sera and Urines from Healthy Subjects

\begin{tabular}{|c|c|c|c|c|c|c|c|}
\hline & \multicolumn{3}{|c|}{ Urine } & & \multicolumn{3}{|c|}{ Serum } \\
\hline & $\gamma \mathrm{G}$ & $\gamma \mathrm{A}$ & $\gamma \mathrm{G} / \gamma \mathrm{A}$ & & $\gamma \mathrm{G}$ & $\gamma \mathbf{A}$ & $\gamma \mathrm{G} / \gamma \mathrm{A}$ \\
\hline & $m g / 24 h r$ & $m g / 24 h r$ & & & $m g / m l$ & $m g / m l$ & \\
\hline M. R. & 2.45 & 0.88 & 2.78 & & 9.00 & 0.58 & 21.47 \\
\hline A. M.* & 3.51 & 1.09 & 3.22 & & 12.45 & 1.12 & 8.04 \\
\hline L. C.* & 1.27 & 1.23 & 1.03 & & 9.30 & 0.77 & 12.08 \\
\hline K. K.* & 2.15 & 1.08 & 1.99 & & 10.70 & 0.49 & 21.84 \\
\hline D. T. & 5.73 & 1.80 & 3.18 & & 14.30 & 1.79 & 7.99 \\
\hline M. A.* & 0.99 & 0.56 & 1.77 & & 5.80 & 1.00 & 5.80 \\
\hline T. T. & 2.39 & 0.67 & 3.57 & & 11.20 & 0.87 & 12.87 \\
\hline T. B. & 4.82 & 2.05 & 2.35 & & 13.80 & 0.90 & 15.33 \\
\hline D. C.* & 3.27 & 0.76 & 4.30 & & 15.00 & 1.26 & 11.90 \\
\hline J. C. & 2.69 & 0.58 & 4.64 & & 15.00 & 1.09 & 13.76 \\
\hline J. S. & 2.90 & 1.03 & 2.82 & & & & \\
\hline J. B. & 2.33 & 1.21 & 1.93 & & & & \\
\hline D. B.* & 1.02 & 1.41 & 0.72 & & & & \\
\hline R. P. & 6.29 & 1.29 & 4.86 & & & & \\
\hline G. D. & 4.46 & 1.20 & 3.72 & & & & \\
\hline A. S. & 2.13 & 1.50 & 1.42 & & & & \\
\hline R. C. & 2.87 & 0.37 & 7.76 & & & & \\
\hline A. S. & 3.88 & 1.23 & 3.15 & & & & \\
\hline A. A. & 1.81 & 1.04 & 1.74 & & & & \\
\hline Total $(n=19)$ & 59.96 & 20.98 & 56.95 & $(\mathrm{n}=10)$ & 116.55 & 9.87 & 131.08 \\
\hline Mean & 3.00 & 1.10 & 3.00 & & 11.65 & 0.99 & 13.11 \\
\hline \multicolumn{8}{|l|}{ Variance } \\
\hline Paired $t$ & & & 1.28 & & & & 28.82 \\
\hline Unpaired $t(\mathrm{n}=19)$ & & & 2.71 & & & $(n=10)$ & 28.82 \\
\hline $\begin{array}{l}\text { Standard deviation } \\
\text { Paired } t\end{array}$ & & & $i .13$ & & & & 5.37 \\
\hline Unpaired $t(\mathrm{n}=19)$ & & & 1.65 & & & $(\mathrm{n}=10)$ & 5.37 \\
\hline
\end{tabular}

Student paired $t$ test on 10 paired serum and urine samples, $P<0.001$.

Unpaired $t$ test with 19 urines and 10 sera, $P<0.001$.

* Females.

vidual ratios of $\gamma \mathrm{G}$ to $\gamma \mathrm{A}$ were calculated and gave a mean value of $3: 1$; this value differs significantly from the values usually found in normal serum. When Student's paired $t$ test (19) was used to compare $\gamma \mathrm{G} / \gamma \mathrm{A}$ ratios on 10 paired serum and urine samples the degree of significance as indicated by $P$ was less than 0.001 . The unpaired $t$ test with 17 degrees of freedom for the 19 urines also showed a $P$ value of less than 0.001 . It should be emphasized that the serum values for the 10 individuals tested have a greater standard deviation than usual. The mean value of the $\gamma \mathrm{G} / \gamma \mathrm{A}$ ratio for normal serum if a large enough population is utilized is $6-8: 1(20)$.

\section{DISCUSSION}

Urinary $\gamma \mathrm{A}$ has been isolated free of other immunoglobulins and found to have a sedimentation coefficient of approximately $11 \mathrm{~S}$. It is not dissociated by $\beta$-mercaptoethanol as are the $\gamma \mathrm{A}$ polymers found in small amounts in normal serum and large amounts in certain myeloma sera. Urinary $\gamma \mathrm{A}$ contains secretory "piece" determinants and seems to be analogous to the secretory $\gamma \mathrm{A}$ so far thought to be characteristic of external secretions.

Previous investigators have described the presence of $\gamma \mathrm{A}$ in normal urine $(8,21,22)$. However, little effort has been made in these studies to char- 
acterize the urinary $\gamma \mathrm{A}$-molecule though there has been some evidence reported which our results confirm and extend. Tomasi and Zigelbaum (7) showed on density gradient ultracentrifugation that urinary $\gamma \mathrm{A}$ had intermediate sedimentation characteristics (approximately 10S). Turner and Rowe have confirmed (8) that urinary $\gamma \mathrm{A}$ occupies an elution position on Sephadex G-200 gel filtration characteristic of an $11 \mathrm{~S}$ molecule

In certain external secretions the $\gamma \mathrm{A}$-immunoglobulins have been shown to predominate $(9,23)$ Unique antigenic determinants which confer upon the secretory $\gamma \mathrm{A}$-molecule antigenic specificity have been found to be due to a polypeptide chain referred to as secretory "piece." The role of secretory "piece" in relation to transport and other biological functions is as yet obscure. It has been suggested that $\gamma \mathrm{A}$ may be synthesized locally by interstitial plasma cells rather than derived from plasma, and that in transit across the epithelial cells to the glandular lumen, secretory "piece" might be added (9). Supporting evidence for this theory comes from the immunofluorescent studies of salivary glands in which secretory "piece" staining occurred only in epithelial cells, whereas $\gamma \mathrm{A}$ was found in plasma cells in the interstitium of the gland (9). Further evidence has been obtained by South, Cooper, Wollheim, Hong, and Good (4) who demonstrated that $\gamma \mathrm{A}$ was not found in the saliva of agammaglobulinemic patients, whereas free secretory "piece" was always detected. However, some specific transport of $\gamma \mathrm{A}$ from serum to saliva did occur when high serum levels were obtained by infusion.

That secretory "piece" can be secreted independently of $\gamma \mathrm{A}$ is evidenced by the finding of free "piece" in the urine (18) and saliva (24) of patients with agammaglobulinemia. Secretory "piece" antigenic determinants have been demonstrated in ureteric urine in the present study. Whether these represent free "piece," that present as part of the $11 \mathrm{~S}$ secretory molecule, or both has yet to be determined. Thus, secretory "piece" might be independently secreted somewhere along the upper renal tract, as has been suggested for the Tamm Horsfall protein. In the latter case it is secreted by the distal renal tubular epithelium (25). In the case of ureteric urine serum type $\gamma \mathrm{A}$ can coexist with unattached secretory "piece." This suggestion has been confirmed by experi- ments ${ }^{6}$ in which isolated secretory "piece" from agammaglobulinemic urine and also that isolated from reduced and alkylated colostral $\gamma \mathrm{A}$ was incubated with serum $\gamma \mathrm{A}$ in the presence and absence of reducing agents. Subsequent immunoelectrophoresis did not demonstrate attachment of secretory "piece" to $\gamma \mathrm{A}$. It may be, therefore, that the formation of secretory $\gamma \mathrm{A}$ is more complex than the simple production of a secretory "piece" with nonspecific affinity for serum type $\gamma \mathrm{A}$ although more work is certainly needed to exclude this possibility, particularly in view of the known ability of $\gamma \mathrm{A}$ to complex with various molecules such as albumin (26). It would seem to us, however, that glomerular leakage of serum type $\gamma \mathrm{A}$ with subsequent chance association with secretory "piece" is not the most likely explanation to account for production of urinary $\gamma \mathrm{A}$.

Two additional explanations to account for the uniform excretion of unattached secretory "piece" in normal urine may be entertained. It is possible that free "piece" circulates in normal plasma, and selective renal excretion occurs similar to that postulated for free $\mathrm{L}$ chains $(1,27)$. However, secretory "piece" cannot be detected by double diffusion in agar in normal human serum concentrated 30 times. $^{7}$ An alternative explanation is that free secretory "piece" is formed from the breakdown of secretory $\gamma \mathrm{A}$ by urinary enzymes. This explanation appears unlikely since secretory $\gamma \mathrm{A}$ isolated from colostrum or saliva has been shown to be relatively resistant to the action of proteolytic enzymes ${ }^{8}(18)$. In addition, no low molecular weight $\gamma \mathrm{A}$-reactive molecules have been detected in concentrated normal urine although degradation into immunologically nonreactive fragments cannot be excluded.

That urinary $\gamma \mathrm{A}$ may participate in immune defense mechanisms is suggested by the recent observations of Tourville, Bienenstock, and Tomasi ${ }^{9}$ who demonstrated $\gamma \mathrm{A}$-antibodies in normal

${ }^{6}$ Tomasi, T. B., and J. Bienenstock. Unpublished observations.

7 Bienenstock, J., and T. B. Tomasi. Unpublished observations.

8 Plaut, A., J. Bienenstock, and T. B. Tomasi. Heat inactivation of gastrointestinal enzymes capable of degrading immunoglobulins. Submitted for publication.

${ }^{9}$ Tourville, D. R., J. Bienenstock, and T. B. Tomasi. Natural antibodies of human serum, saliva, and urine reactive with Escherichia coli. Submitted for publication. 
urine against $E$. coli. In immunized individuals $\gamma \mathrm{A}$-urinary antibodies have been demonstrated against $S$. typhi (28), polio virus (29), and tetanus toxoid (8). In addition, a $\gamma \mathrm{A}$-rheumatoid factor has been isolated from the urines of patients with high serum titers of rheumatoid factor and a total $24 \mathrm{hr}$ urinary protein excretion of less than $80 \mathrm{mg}$ (30).

It is interesting to note that in 1948 on the basis of experiments with cholera vaccine Burrows and Havens (31) concluded that urinary and fecal antibody were independent of serum antibody and, therefore, not derived from it, at least directly by transudation. A $\gamma \mathrm{G} / \gamma \mathrm{A}$ ratio which differs from that found in serum has been shown to occur in urine, and because of difficulties in quantitating $\gamma \mathrm{G}$ (outlined under Results) it is possible that the $\gamma \mathrm{A}$ class of immunoglobulins predominates in the urine as it does in other external secretions. Granted that secretion of $\gamma \mathrm{A}$ occurs along the urinary tract; then with the demonstration of "piece" determinants in ureteric urine in this study the upper renal tract might be thought to be the major source. It is still possible, however, that the lower urinary tract participates in the formation of secretory "piece," secretory $\gamma \mathrm{A}$, or both. The possibility that local synthesis of secretory $\gamma \mathrm{A}$ occurs somewhere along the urinary tract is presently under active investigation.

\section{ACKNOWLEDGMENTS}

The authors greatly acknowledge the help and statistical analysis of Dr. D. L. Sackett of the Clinical Epidemiology Unit, Department of Medicine and Preventive Medicine, State University of New York at Buffalo.

This work was supported by U. S. Public Health Service Grant 7 RO1 AM-10419 and the Buswell Fellowship of the State University of New York at Buffalo.

\section{REFERENCES}

1. Berggard, I. 1961. On a $\gamma$ globulin of low molecular weight in normal human plasma and urine. Clin. Chim. Acta. 6: 545.

2. Vaughan, J. H., R. F. Jacox, and B. A. Gray. 1967. Light and heavy chain components of gamma globulins in urines of normal persons and patients with agammaglobulinemia. J. Clin. Invest. 46: 266.

3. Franklin, E. C. 1959. Physicochemical and immunologic studies of gamma globulins of normal human urine. J. Clin. Invest. 38: 2159.

4. Berggard, I., and H. Bennich. 1967. Fc fragment of immunoglobulin $G$ in normal human plasma and urine. Nature. 214: 697.
5. Turner, M. W., and D. S. Rowe. 1966. A naturally occurring fragment related to the heavy chains of immunoglobulin $\mathrm{G}$ in normal human urine. Nature. 210: 120 .

6. Bienenstock, J. Urinary $F c$ and $F^{\prime} c$ fragments. $J$. Immunol. In press.

7. Tomasi, T. B., Jr., and S. Zigelbaum. 1963. The selective occurrence of $\gamma \mathrm{A}$ globulins in certain body fluids. J. Clin. Invest. 42: 1552.

8. Turner, M. W., and D. S. Rowe. 1967. Antibodies of IgA and IgG class in normal human urine. Immunology. 12: 689 .

9. Tomasi, T. B., E. M. Tan, A. Solomon, and R. A. Prendergast. 1965. Characteristics of an immune system common to certain external secretions. J. Exptl. Med. 121: 101 .

10. Lowry, O. H., N. J. Rosebrough, A. L. Farr, and R. J. Randall. Protein measurement with the Folin phenol reagent. J. Biol. Chem. 193: 265.

11. Kabat, E. A., and M. M. Mayer. 1961. Experimental Immunochemistry. Charles C Thomas, Publisher, Springfield, Ill. 2nd edition.

12. Poulik, M. D. 1966. $\mathrm{F}^{\prime} \mathrm{c}$ fragment of immunoglobulins. Nature. 210: 133.

13. Bienenstock, J., and K. J. Bloch. 1966. Some characteristics of human immunoconglutinin. J. Immunol. 99: 637.

14. Tomasi, T., and H. G. Kunkel. 1964. I. Isolation of 7S and 19S gamma globulins. In Methods in Medical Research. Year Book Medical Publishers, Inc., Chicago, Ill. 10: 80.

15. Everall, P. H., and G. H. Wright. 1958. Low pressure ultrafiltration of protein containing fluids. $J$. Med. Lab. Technol. 15: 209.

16. Poortmans, J., and J. Van Fraechem. 1965. Influence de certaines techniques de conservation et de concentration des urines vis-à-vis de l'intégrité des proteines plasmatiques. Clin. Chim. Acta. 12: 114.

17. Miyasato, F., and V. E. Pollak. 1966. Serum proteins in urine: an examination of the effects of some methods used to concentrate the urine. J. Lab. Clin. Med. 67: 1036.

18. Tomasi, T. B., and D. S. Czerwinski. 1967. The selective secretion of antibodies. Third Developmental Immunology Workshop, Sanibel Island, Fla.

19. Snedecor, G. W. 1956. Statistical Methods Applied to Experiments in Agriculture and Biology. Iowa State University Press, Ames, Iowa. 5th edition.

20. Tomasi, T. B., Jr. 1965. Human gamma globulin. Blood. 25 : 382.

21. Berggard, I. 1961. Studies on the plasma proteins in normal human urine. Clin. Chim. Acta. 6: 413.

22. Hanson, L. A., and E. M. Tan. 1965. Characterization of antibodies in human urine. J. Clin. Invest. 44: 703.

23. Chodirker, W. B., and T. B. Tomasi, Jr. 1963. Gamma-globulins: quantitative relationships in human serum and non-vascular fluids. Science. 142: 1080. 
24. South, M. A., M. D. Cooper, F. A. Wollheim, R. Hong, and R. A. Good. 1966. The IgA system. I. Studies of the transport and immunochemistry of $\operatorname{IgA}$ in the saliva. J. Exptl. Med. 123: 615.

25. Hermann, G. 1966. Quoted by H. E. Schultze and J. F. Heremans: The urinary proteins. In Molecular Biology of Human Proteins. American Elsevier Publishing Co., Inc., New York. 1.

26. Heremans, J. 1960. Les globulines seriques du système gamma: leur nature et leur pathologie. Arscia, Brussels.

27. Solomon, A., T. A. Waldmann, J. L. Fahey, and A. S. McFarlane. 1964. Metabolism of Bence Jones proteins. J. Clin. Invest. 43: 103.

28. Turner, M. W., and D. S. Rowe. 1964. Characteriza- tion of human antibodies to Salmonella typhi by gelfiltration and antigenic analysis. Immunology. 7: 639.

29. Berger, R., E. Ainbender, H. L. Hodes, H. D. Zepp, and M. M. Hevizy. 1967. Demonstration of IgA polioantibody in saliva, duodenal fluid and urine. Nature. 214: 420 .

30. Bienenstock, J., and T. B. Tomasi. 1967. $\gamma$ A rheumatoid factor in urine. Proceedings from the 4th Panamerican Congress on Rheumatology, Mexico City, Mex.

31. Burrows, W., and I. Havens. 1948. Studies on immunity to Asiatic cholera. V. The absorption of immune globulin from the bowel and its excretion in the urine and feces of experimental animals and human volunteers. J. Infect. Diseases. 82: 231. 